\title{
OCULAR FINDINGS IN PATIENTS WITH CHRONIC RENAL DISEASE
}

\author{
Manjula Devi', Hemalatha Krishnamurthy22, Gajaraj Naik3, Pradeep Kumar S. M4, Mahima S. R5, Chandresh Suthar6, \\ Bhoomika Dhanani ${ }^{7}$, Srividya $B^{8}$
}

\begin{abstract}
${ }^{1}$ Associate Professor, Department of Ophthalmology, Mysore Medical College and Research Institute, Mysore. ${ }^{2}$ Associate Professor, Department of Ophthalmology, Mysore Medical College and Research Institute, Mysore. 3 Junior Resident, Department of Ophthalmology, Mysore Medical College and Research Institute, Mysore. ${ }^{4}$ Junior Resident, Department of Ophthalmology, Mysore Medical College and Research Institute, Mysore. 5Junior Resident, Department of Ophthalmology, Mysore Medical College and Research Institute, Mysore. 6Junior Resident, Department of Ophthalmology, Mysore Medical College and Research Institute, Mysore. 7 Junior Resident, Department of Ophthalmology, Mysore Medical College and Research Institute, Mysore. 8Junior Resident, Department of Ophthalmology, Mysore Medical College and Research Institute, Mysore.
\end{abstract}

\section{ABSTRACT}

\section{BACKGROUND}

Chronic renal failure (CRF) affects every organ system including eye. It is a growing global public health problem which affects $10 \%-16 \%$ of population in Asia, Australia, Europe and United states. The aim of this study was to prospectively analyse the ocular changes among CRF patients and to evaluate patients for any visual threat, especially from retinopathy so that timely necessary advice and treatment be given before irreversible visual loss occurs.

\section{MATERIALS AND METHODS}

In this study, 100 cases with CRF were collected from nephrology and medicine departments of K. R. Hospital, MMC and RI, Mysore between $1^{\text {st }}$ November 2016 and 30th April 2017 and a descriptive study was conducted.

\section{RESULTS}

The results were analysed; 40 - 60 years' age group was commonly affected with a definite male preponderance (80\%). The most common cause leading to CRF in these patients was combined form (diabetes and hypertension) $40 \%$, hypertension $25 \%$, diabetes $16 \%$ and others $16 \%$. The major causes for visual impairment was cataract $(14 \%)$ followed by diabetic retinopathy with maculopathy in $16(8 \%)$, PDR in $2(1 \%)$, optic neuropathy in $1(0.5 \%)$, resolving vitreous haemorrhage in 2 (1\%), BRVO in 1 $(0.5 \%)$, corneal calcification in 3 and opacification in 1 (2\%) and ARMD in 5 (2.5\%). Lid oedema in 44\%, conjunctival findings in $54 \%$ and corneal calcification was present in 3\%. Hypertensive retinopathy in 32 out of 68 hypertensives (47.06\%) and diabetic retinopathy in 32 out of 56 diabetic cases (57.13\%) was noted. Diabetic retinopathy was more prevalent and this was statistically significant. There were two cases of bilateral serous retinal detachment related to chronic renal failure.

\section{CONCLUSION}

Retinopathy is very often asymptomatic in its treatable early stage. An early diagnosis of sight threatening retinal conditions and its timely intervention can significantly decrease the patient's risk of irreversible visual loss. Ocular evaluation of CRF patients in their early stages is important, as significant number of patients in this study were advised treatment so that visual impairment could be prevented.

\section{KEYWORDS}

Albuminuric Retinitis, Chronic Renal Failure, Corneal Calcification, India, Retinopathy.

HOW TO CITE THIS ARTICLE: Devi M, Krishnamurthy H, Naik G, et al. Ocular findings in patients with chronic renal disease. J. Evolution Med. Dent. Sci. 2017;6(79):5626-5631, DOI: 10.14260/jemds/2017/1220

\section{BACKGROUND}

Chronic renal failure is an irreversible deterioration of renal function. It is a growing global public health problem, which affects $10 \%-16 \%$ of population in Asia, Australia, Europe and United states.[1] Prevalence of chronic kidney disease in Indian population is $0.79 \%$. It is defined as the presence of either kidney damage or glomerular filtration rate (GFR) $<60$ $\mathrm{mL} / \mathrm{min} / 1.73$. $^{2}$

'Financial or Other Competing Interest': None.

Submission 18-08-2017, Peer Review 19-09-2017,

Acceptance 25-09-2017, Published 30-09-2017.

Corresponding Author:

Dr. Hemalatha Krishnamurthy,

Flat No. 211, Second Floor,

D. S. Max Smaran Apartment

Industrial Suburb, Third Stage,

Vishweshwar Nagar, Mysore-570008.

E-mail:dr.hemalatha_k@yahoo.in

DOI: $10.14260 /$ jemds $/ 2017 / 1220$
Chronic kidney disease [CKD] is associated with chronic conditions including cardiovascular disease, ${ }^{[2]}$ cancer ${ }^{[3]}$ and cognitive dysfunction. ${ }^{[4]}$ Bright, in 1836, was the first to associate renal disease with blindness. Liebreich, in 1859, described fundus changes in uraemic patients and subsequently this condition was named Bright's disease or albuminuric retinitis.[5] Deterioration of eyesight is due to worsening of hypertensive or diabetic retinopathy, ischaemic optic neuropathy, central retinal vein occlusion and cortical blindness. By the ESRD, $80.0 \%$ of patients will have developed secondary HTN.[6] Ocular morbidity may be directly due to HTN, uraemia and anaemia; some are related to the causes leading to chronic renal failure; some effects are due to haemodialysis.

Important ocular finding related to renal insufficiency are lid oedema, conjunctival pallor and xanthelasma which are associated with increased serum lipids. Corneal and conjunctival calcification may also occur due to secondary 
hyperparathyroidism. Inflammatory reactions of conjunctiva and episclera can be associated with a sudden, marked rise in serum calcium. [7,8] Conjunctival degenerative changes, e.g. pinguecula are frequently seen in CRF. ${ }^{[9]}$ Goblet cell density is decreased.[10] Recurrent subconjuctival haemorrhage can occur due to sclerosed conjunctival vessels secondary to HTN.[2] Rubeosis iridis and neovascular glaucoma occur due to the posterior segment pathology. Rising concentrations of intracellular calcium might contribute to early cataractogenesis and calcium deposition in lens.[11]

Hypertensive retinopathic changes are particularly severe in renal failure. This has been attributed to the effects of retained nitrogen products.[11] Accelerated hypertension can result in optic disc oedema.[12] The ophthalmic appearance is of value in determining the efficacy of the antihypertensive therapy. ${ }^{[13]}$ The retina is accessible to monitor status of blood pressure control.[11] Blindness due to proliferative retinopathy or maculopathy is approximately five times more common in diabetic patients with nephropathy compared with normoalbuminuric patients.[14] Diabetic retinopathy (DR) tends to deteriorate with falling renal function, poorly controlled blood pressure ${ }^{[15,16]}$ and in patients in whom no retinal treatment has been given before. ${ }^{[17,18]}$ Several cases of bullous retinal detachment have been reported in CRF, which could be from deranged metabolism, uncontrolled blood pressure and retinal pigment epithelium dysfunction.[16,17] Both anterior and posterior optic neuropathy can occur in CRF. When haemoglobin level falls below $5 \mathrm{gm} \%$, retinopathic features like retinal haemorrhages, hard and soft exudates and pallor of optic discs (ischaemic optic neuropathy) could be present. The retinal arterioles look pale, the vein distended.

Retinopathy is often asymptomatic in its most treatable stage; delay in diagnosis can result in significant increase in the patient's risk of visual loss.[16] Ocular condition is also an indicator of the metabolic control of the disease process. Similarly, an unknown case of chronic renal failure with its ocular complications may first present to an ophthalmologist. This study is an attempt to access the ocular status/ complications associated with CRF. It is intended to highlight the importance of ocular examination, to screen patients for any potential visual threat so that necessary treatment and/or advice can be given before they become irreversibly visually impaired.

\section{MATERIALS AND METHODS}

In our study, 100 patients diagnosed as chronic kidney disease (CKD) attending Nephrology and Medicine Department, K. R. Hospital, Mysore Medical Collage and Research Institute, Mysore, South India were enrolled. Period of study was 6 months (1st November 2016 to April 30 th 2017). Patients not willing to undergo dilated fundus examination, age group less than 18 yrs. and CKD patients on dialysis were excluded. The statistical methods Cramer's for association, Chi-square for difference and SPSS version 16.0 were used in this descriptive study.

All patients were enrolled for the study after obtaining a written and informed consent. Detailed anterior segment examination was done by slit lamp biomicroscopy and posterior segment examination by direct and indirect ophthalmoscopy. Visual acuity and intraocular tension recording were done. Investigations like complete haemogram, blood urea, serum creatinine, serum calcium, serum phosphate, serum potassium, urine microscopy, albumin and sugar were done. Estimated glomerular filtration rate (eGFR) was calculated using the Chronic Kidney Disease Epidemiology Collaboration (CKDEPI) equation. Cases were classified as mild, moderate, severe and ESRD if GFR is between 30 to $50 \mathrm{~mL} / \mathrm{min} ; 10$ to $29 \mathrm{~mL} / \mathrm{min}$; 5 to 9 $\mathrm{mL} / \mathrm{min}$, less than $5 \mathrm{~mL} / \mathrm{min}$ respectively. Systemic history regarding different causes of chronic renal disease was taken. Hypertensive retinopathy (HR) was graded on the basis of Keith and Wagener classification. Diabetic retinopathy (DR) and macular oedema was classified on the basis of early treatment diabetic retinopathy study. Ethical committee clearance was obtained.

\section{RESULTS}

Among total of 100 patients with CRF, the sample size in each grade of CRF were as follows: Mild 25 cases (25\%), moderate 18 cases (18\%), severe 9 cases (9\%) and ESRD 48 cases (48\%). Mean age of total patients of CRF was $50.76+9.923$ years and $\mathrm{M}$ : $\mathrm{F}$ ratio was 8.09: 1 showing a male preponderance. Similar demographic parameters were obtained in each of the subgroups. The commonest cause of CRF were both HTN and Diabetes in 40 (40\%), only hypertension in $28(28 \%)$ followed by Diabetes in $16(16 \%)$ and others $16(16 \%)$. Other causes were glomerulonephritis, snake bite and calculus.

Ocular symptoms in patients of CRF: Blurring of vision was the most important symptom complained by $52.0 \%$ of patients. Most of it (46.0\%) was of gradual onset. Other problems were irritative symptoms (19.4\%) and red eyes (2.0\%). In spite of this, $46.3 \%$ of patients have never had eye checkup before. Only $15.2 \%$ of patients had detailed ocular examination (both anterior and posterior segment) evaluation in the past. According to WHO criteria in this study $76 \%$ were with vision $6 / 18$ or better, $16 \%$ were visually impaired and another $08 \%$ were in the category of legally blind (vision, $<6 / 60$ ). P value was not significant for visual loss with the severity of renal failure. Table 1 shows the best corrected visual acuity.

The major causes for vision less than $6 / 18$ was cataract (14\%) followed by diabetic retinopathy with maculopathy in $16(8 \%)$, PDR in 2 (1\%), optic neuropathy in $1(0.5 \%)$, resolving vitreous haemorrhage in $2(1 \%)$, BRVO in $1(0.5 \%)$, corneal calcification in 3 and opacification in 1 (2\%) and ARMD in 5 (2.5\%). Table 2 shows major causes for vision less than $6 / 18$. Tables 3 and 4 respectively show anterior and posterior segment findings related to CRF.

In the present study, $32(57.14 \%)$ out of 56 diabetic patients (40 of combined HTN and DM+ 16 only diabetic) with CRF had diabetic retinopathy. DR mild $4 \%$, moderate $9 \%$, severe $9 \%$, very severe $8 \%$, PDR $1 \%$ and HR PDR $1 \%$ were the different grades observed in CRF cases.

In the present study, $32(47.06 \%)$ patients out of 68 total hypertensives (40 combined HTN and DM + only hypertensives 28) with CRF had hypertensive retinopathy. There were 2 cases of severe CRF with bilateral exudative type of retinal detachment. Hyperlipidaemia was seen among $34 \%$. Tables 5 and 6 compare the grades of HR and DR with severity of renal failure respectively. 
Significant findings present along with the higher grades of $\mathrm{CRF}$ were lid oedema ( $\mathrm{P}=0.0043$ ), conjunctival findings which included pinguecula, congestion and dry eye $(\mathrm{P}=0.022)$, corneal calcification $(\mathrm{P}=0.003)$, diabetic retinopathy $(\mathrm{P}=0.001)$ and hypertensive retinopathy $(\mathrm{P}=0.003)$.
The distribution of intraocular pressure (IOP) among the patients of CRF was found to be the normal bell shaped curve with skewness to the right. Mean IOP was $13.7+3.3 \mathrm{mmHg}$. The mean values of serum calcium, serum potassium, serum phosphate are $9.6+/-0.61 \mathrm{mg} / \mathrm{dL}, 4.09+/-0.67 \mathrm{mEq} / \mathrm{L}$ and $4.46+/-0.48 \mathrm{mg} / \mathrm{dL}$ respectively.

\begin{tabular}{|c|c|c|c|c|c|c|c|}
\hline WHO Criteria & Grades of CRF Visual Acuity & Mild & Moderate & Severe & ESRD & Total & $\%$ of Total Eyes \\
\hline Good vision & $>6 / 18$ & 42 & 28 & 10 & 72 & 152 & $76 \%$ \\
\hline $\begin{array}{l}\text { Impaired } \\
\text { vision }\end{array}$ & $6 / 60-6 / 24$ & 5 & 3 & 2 & 22 & 32 & $16 \%$ \\
\hline Legally blind & $<6 / 60$ & 3 & 5 & 6 & 2 & 16 & $8 \%$ \\
\hline & & 50 & 36 & 18 & 96 & 200 & 100.0 \\
\hline
\end{tabular}

${ }^{*} \mathrm{P}$ value $=0.395,{ }^{* *} \mathrm{P}$ value $=0.499$, Level of Significance: $\mathrm{P}<0.05$ at $95.0 \%$ confidence limit.

\begin{tabular}{|c|c|c|}
\hline Cause of Visual Impairment & No. of Eyes & \% of Total Eyes out of 200 \\
\hline Corneal calcification/scar & 4 & $2 \%$ \\
\hline Cataract & 28 & $14 \%$ \\
\hline Vitreous haemorrhage & 2 & - \\
\hline Diabetic retinopathy with & - & $8 \%$ \\
Maculopathy & 16 & $1 \%$ \\
PDR & 2 & $0.5 \%$ \\
Optic neuropathy & 1 & $2.5 \%$ \\
\hline ARMD & 5 & $\mathbf{2 9 \%}$ \\
\hline Table 2. Causes of Visual Impairment (Corrected Visual Acuity less than 6/18) in CRF
\end{tabular}

\begin{tabular}{|c|c|c|c|c|c|c|}
\hline Grades of CRF Ocular Findings & Mild & Moderate & Severe & ESRD & Total & P value \\
\hline Lid oedema & 8 & 9 & 13 & 14 & 44 & $0.043^{*}$ \\
\hline $\begin{array}{c}\text { Conjunctival findings } \\
\text { (congestion, pinguecula, dry eye) }\end{array}$ & 9 & 11 & 15 & 19 & 54 & $0.022^{*}$ \\
\hline Corneal calcification & 0 & 0 & 0 & 3 & 3 & $0.003^{*}$ \\
\hline Elevated IOP & 1 & 0 & 0 & 2 & 3 & 0.674 \\
\hline Cataract & 14 & 6 & 4 & 4 & 28 & 0.785 \\
\hline
\end{tabular}

*Significant, Level of Significance: $\mathrm{P}<0.05$ at $95.0 \%$ confidence limit.

\begin{tabular}{|c|c|c|c|c|c|c|}
\hline $\begin{array}{c}\text { Grades of CRF Ocular } \\
\text { Findings }\end{array}$ & Mild & Moderate & Severe & ESRD & Total & P value \\
\hline Vitreous haemorrhage & 0 & 0 & 1 & 1 & 2 & 0.319 \\
\hline Optic neuropathy & 0 & 0 & 1 & 0 & 1 & 0.111 \\
\hline Diabetic retinopathy & 1 & 0 & 3 & 15 & 27 & $0.003^{*}$ \\
\hline $\begin{array}{c}\text { Hypertensive } \\
\text { retinopathy }\end{array}$ & 0 & 3 & 2 & 27 & $0.001^{*}$ \\
\hline Bullous RD & 0 & 1 & 0 & 1 & 2 & 0.324 \\
\hline BRVO & 0 & 0 & 1 & 0 & 1 & 0.632 \\
\hline ARMD & 3 & 1 & 0 & 1 & 5 & 0.316 \\
\hline Glaucoma suspect & 1 & 0 & 1 & 0 & 2 & 0.654 \\
\hline
\end{tabular}

Significant Level of Significance: $\mathrm{P}<0.05$ at $95 \%$ confidence limit.

\begin{tabular}{|c|c|c|c|c|c|}
\hline $\begin{array}{c}\text { Grades of CRF } \\
\text { Grades of HR }\end{array}$ & Mild & Moderate & Severe & ESRD & Total \\
\hline 1 & 2 & 3 & 1 & 4 & 10 \\
\hline 2 & 2 & 2 & 1 & 3 & 8 \\
\hline 3 & 0 & 2 & 4 & 3 & 11 \\
\hline 4 & 0 & 0 & 0 & $\mathbf{1 5}$ & 3 \\
\hline Total cases of HR & $\mathbf{7}$ & $\mathbf{6}$ & $\mathbf{3 2}$ \\
\hline
\end{tabular}




\begin{tabular}{|c|c|c|c|c|c|}
\hline Grades of CRF Grades of DR & Mild & Moderate & Severe & ESRD & Total \\
\hline Mild & 0 & 0 & 2 & 2 & 4 \\
\hline Moderate & 1 & 3 & 2 & 3 & 9 \\
\hline Severe & 0 & 2 & 2 & 5 & 9 \\
\hline Very Severe & 0 & 2 & 4 & 2 & 8 \\
\hline PDR & 0 & 0 & 1 & 0 & 1 \\
\hline HR PDR & 0 & 0 & 0 & 1 & 1 \\
\hline Total & 1 & 7 & 11 & 13 & 32 \\
\hline
\end{tabular}

\section{DISCUSSION}

CRF can occur at any age and in this condition slowly progressive deterioration of renal function is seen. ${ }^{[19]}$ Highest no. of patients were in the age group between $40-60 \mathrm{yrs}$. with mean age of $50.76+9.923$ years, which is consistent with the study done by L. Bajracharya et al $(48.3+/-14.9)$ years. [20]

M: F ratio was 8.09: 1 showing a male preponderance, which was significantly more compared to the worldwide data.[1] The reason for this could be due to high prevalence of diabetes and hypertension among males in India due to change in lifestyle and faster rate of deterioration of kidney function in male with some forms of glomerulonephritis.

In the present study, each grade of CRF were as followsmild 25 cases (25\%), moderate 18 cases (18\%), severe 9 cases (9\%) and ESRD 48 cases (48). The commonest cause of CRF was combined HTN and Diabetes in $40(40 \%)$, only hypertension in $28(28 \%)$ followed by diabetes $16(16 \%)$ and others 16 (16\%). Other causes were glomerulonephritis, snake bite and calculus. These results are in concordance with the study of L. Bajracharya et al, where the commonest cause of CRF was HTN 43 out of 119 (36.1\%) followed by DM (27.7\%) and glomerulonephritis (20.2\%).[20] Hyperlipidaemia was seen in $34 \%$ of cases.

Diminished vision was the most common ocular symptom observed in $52 \%$ of patients, which correlates with the study by L. Bajracharya et al and Manjula S et al.[20,19] In the present study, out of 200 eyes examined BCVA $>6 / 18$ was present in $76 \%$ of eyes, $16 \%$ eyes had visual acuity between $6 / 24$ and $6 / 60$ and $8 \%$ had BCVA less than $6 / 60$. This is in concordance with the study by L. Bajracharya et al[20] and our patients had better visual status compared to study done by Manjula B et al. They report BCVA > 6/18 present in 23\%, 49.5\% between $6 / 24$ and $6 / 60,27.5 \%<6 / 60$ and $77 \%$ had visual acuity < 6/18.[19] However, visual acuity is not the sole indicator of the ocular status. Even advanced DR and HR may have good central vision until macula is involved. In this study, 2 out of 3 patients of grade IV HR and 2 out of 11 patients with grade III HR had quite good vision, but they were at risk of visual loss due to disc oedema in 2 cases, resolving vitreous haemorrhage in 1 case and BRVO in 1 case. In our study, cataract accounts for major cause of visual loss in 28 eyes (14\%) followed by diabetic retinopathy with maculopathy in $16(8 \%)$, PDR in 2 (1\%), optic neuropathy in $1(0.5 \%)$, resolving vitreous haemorrhage in $2(1 \%)$, BRVO in $1(0.5 \%)$, corneal calcification and opacification in $4(2 \%)$ and ARMD in $5(2.5 \%)$. P value was not significant for cataract when compared with different grades of CRF. L. Bajracharya et al has reported maculopathy as the cause of visual impairment in 23 eyes out of 238 eyes (9.7\%) followed by cataract in 14 (5.9\%) eyes, PDR in 9 (3.8\%) eyes. Our observation also reveals the same causes.[20] Greater incidence of cataract may be explained by the presence of more number of patients in stage 4 in this study. Higher levels of oxidised glutathione in CRF patients in severe stages exposes the lens to oxidative stress, which may be another one possible reason. The higher incidence of diabetes among patients included may be another possible reason for higher incidence of cataract.[19]

Most of the patients were having complaints of blurring of vision (52.0\%). Overall, only $43.7 \%$ had gone for eye checkup. This obviously showed the lack of knowledge about the potential ocular complications in chronic renal disease patients; $58.6 \%$ of patients in ESRD compared to $29.0 \%$ in mild group had undergone ocular examination in the past. This could indicate increasing ocular problems with advancing renal disease.

Lid puffiness and conjunctival involvement were present in $44 \%$ and $54 \%$ of total cases respectively. Being statistically significant, they can be regarded as consistent finding in CRF. In $3 \%$ of patients in ESRD group, corneo-conjunctival calcium deposits were present. Study done by Bajracharya et al[20] reported $1.6 \%$ and study by Narendranath Reddy reported $1.75 \%$ corneal calcification in their patients.[21] These studies concord with our study. There was no correlation between ocular surface calcification and mean serum values of calcium, potassium and phosphate that were observed. One of the important complication of CRF is disturbance of the mineral metabolism, i.e. secondary hyperparathyroidism. Soft tissue calcification is a common feature of mineral metabolism disturbance in CRF. The pathogenesis of ocular calcifications is not completely understood, but are most frequently observed. Vrabec R et al reports 9 patients (14\%) with corneo-conjunctival calcium deposits in CRF patients on haemodialysis.[22] The reports of other studies by Bourquia et al states $36.0 \%$ of their patients had corneal and conjunctival calcifications. ${ }^{[23]}$ The studies by Pahor D et al[24] and Michaud PA et $\mathrm{al}^{[25]}$ showed that calcification occurs in $60.0 \%$ to $80.0 \%$ of CRF cases. There has been positive correlation of the soft tissue calcification with the duration of haemodialysis. [21]

Mean intraocular pressure in patients of CRF was $13.7+$ $3.3 \mathrm{mmHg}$. In a study done in Italy by Bourquia et al,[23] an average IOP of CRF patients was slightly less than the control group $(14.9+2 \mathrm{mmHg}$ versus $15.6+1.9 \mathrm{mmHg}$ with $\mathrm{P}=0.07)$. Our study did not have control group.

The most important and vision threatening findings were in the posterior segment. Prevalence of retinal pathology was highest among patients with both hypertension and diabetes (40\%) followed by hypertension (28\%) and then by patients with diabetes $(16 \%)$.

In the present study, $47.06 \%$ of total hypertensive patients (combined form 40 patients plus only hypertensives 28 patients) with CRF had hypertensive retinopathy. The findings in this study concords with the studies done by L. Bajracharya et al, where they report $47.10 \%$ had HR. HR was more prevalent as the renal disease progressed. Grade IV HR 
with optic disc oedema was present only in severe CRF and ESRD and seen in 2 cases. Similarly, 9 out of 11 in Grade III HR was detected in severe CRF and ESRD together. Hypertensive retinopathy changes are severe, particularly in patients with renal failure and this has been attributed to the effects of retained nitrogen products. The retina is easily accessible to monitor status of blood pressure control.[12] Accelerated hypertension leads to optic disc oedema.[13] Ninety-two percent of grade III HR and hundred percent of grade IV HR were detected for the first time in our study. Grade III and IV HR have bad prognosis and this may alert the physician for more aggressive management of the blood pressure.

In the present study, $57.14 \%$ of total diabetic patients ( 40 of combined form and 16 of only diabetic patients) with CRF had diabetic retinopathy. Observations made in this study does not correlate with observations seen in other studies done by L. Bajracharya et al. They report a little higher prevalence, $88.3 \%$ DR in their series.[20] Mild DR was mostly seen in mild CRF group, but moderate, severe and PDR (proliferate diabetic retinopathy) were seen in higher grades of CRF.

In the study done by Manjula $S$ et al reports majority of their patients had moderate, severe, very severe NPDR that accounted for $13 \%, 14 \%$ and $15 \%$ respectively, which is slightly higher, but our study also had majority in the same group. Although, not statistically proven because of small sample size, these data support previous studies that DR is invariably present in cases of diabetic nephropathy and that more severe forms of retinopathy are detected as renal disease progresses. Overall, 16 eyes had maculopathy, most of which (12 eyes) were related to DR and only 4 were associated with HR and DR. All types of maculopathy- focal, diffuse and chronic were detected. Among newly diagnosed DR there was 2 PDR, 3 severe and one very severe DR, all were never treated before. Many patients from the study received urgent laser treatment whenever necessary in our Medical Retina Clinic at Ophthalmology Department.

Combination Form: In the present study, $40 \%$ of patients with CRF had both hypertensive and diabetes mellitus. Diabetic retinopathy was worse in cases who had both diabetes and hypertension.

There were two cases of bilateral bullous, exudative type of retinal detachment seen in patients with severe grade of renal disease, which was managed with metabolic and blood pressure control. It has been stated that in uraemia, retinal detachment should be regarded as an immediate indication for peritoneal and haemodialysis.[19]

\section{CONCLUSION}

In conclusion, detail ocular examination should be undertaken in patients with CRF. The most common cause of $\mathrm{CRF}$ in our study is combined hypertension and diabetes. Cataract followed by maculopathy is the most commonly observed cause for diminished vision. Retinopathy in its early stages is often asymptomatic, so frequent checkup in all cases of longstanding diabetics and hypertensives is advised. Early diagnosis can result in significant decrease in the patient's risk of visual loss. The retinovascular pathology reflects renal disease, thus revealing the importance of ocular evaluation.

\section{REFERENCES}

[1] Weatherall DJ, Ledingham JGG, Warrell DA. Oxford text book of medicine. Vol III. $3^{\text {rd }}$ edn. Oxford-New YorkTokyo: Oxford Univ Press, 1996:3294-5.

[2] Go AS, Chertow GM, Fan D, et al. Chronic kidney disease and the risks of death, cardiovascular events, and hospitalization. N Engl J Med 2004;351(13):1296305.

[3] Sabanayagam C, Shankar A, Koh D, et al. Retinal microvascular caliber and chronic kidney disease in an Asian population. Am J Epidemiol 2009;169(5):62532.

[4] Kurella Tamura M, Wadley V, Yaffe K, et al. Kidney function and cognitive impairment in US adults: the reasons for geographic and racial differences in stroke (REGARDS) study. Am J Kidney Dis 2008;52(2):22734.

[5] Duke-Elders S, Dohree JH. System of ophthalmology. Chapter 4, $1^{\text {st }}$ edn. Vol X. London: The CV Mosby Company, 1967:315-47.

[6] Stein JH, Hulton JJ, Kohler PO, et al. Internal medicine. $3^{\text {rd }}$ edn. USA: Little Brown \& Comp 1990:809-10.

[7] Klaassen-Broekema N, van Bijsterveld OP. Red eyes in renal failure. Br J Ophthalmol 1992;76(5):268-71.

[8] Klaassen-Broekema N, van Bijsterveld OP. The role of serum calcium in the development of the acute red eye in chronic renal failure. Eur J Ophthalmol 1995;5(1):712.

[9] Cohen SL, Gorchein A, Hayward JA, et al. Pingueculaean association with renal failure. Q J Med 1974;43(170):281-91.

[10] Dursun D, Demirhan B, Oto $S$, et al. Impression cytology of the conjunctival epithelium in patients with chronic renal failure. $\mathrm{Br} \mathrm{J}$ Ophthalmol 2000;84(11):1225-7.

[11] Duane TD, Jaeger EA. Duane's clinical ophthalmology. Revised edn. USA: Harper and Row, 1987:31:1-2.

[12] Ryan SJ, Schachat AP. Medical retina. Vol II. 4th edn. Philadelphia: Elservier Mosby 2006:1271-8, 1377-81.

[13] Peyman GA, Sanders DR, Goldberg MF. Principles and practice of ophthalmology. New Delhi: Jaypee Brothers, 1987:1205-35, 1633-40.

[14] Schrier RW, Gottschalk CW. Diseases of the kidney. Vol I, II, III. $5^{\text {th }}$ edn. Boston-Toronta-London: Little Brown \& Comp, 1993:2180-1.

[15] Schmechel H, Heinrich U. Retinopathy and nephropathy in 772 insulin-treated diabetic patients in relation to the type of diabetes. Diabetes Metab 1993;19(1 Pt 2):138-42.

[16] Albert DM, Jacobiec FA, Azar DT, et al. Principles and practice of ophthalmology. Vol II. $2^{\text {nd }}$ edn. Philadelphia: WB Saunders, 2000:1900-13.

[17] Leys AM. Eye fundus of the diabetic patient with nephropathy and hypertensive retinopathy. Macroangiopathic complications. Bull Soc Belge Ophtalmol 1995;256:49-59.

[18] Friberg TR, Eller AW. Serous retinal detachment resembling central serous chorioretinopathy following organ transplantation. Graefes Arch Clin Exp Ophthalmol 1990;228(4):305-9. 
[19] Manjula B, Khadari MH, Velampalli S. Clinical study of retinal changes in chronic renal failure patients. Journal of Dental and Medical Sciences 2017;16(4): 31-4.

[20] Bajracharya L, Shah DN, Raut KB, et al. Ocular evaluation in patients with chronic renal failure-a hospital based study. Nepal Med Coll J 2008;10(4):209-14.

[21] Narendranath Reddy G, Satyanarayana Reddy M, Premanandam $M$, et al. Ocular manifestations in chronic renal failure patients. JMSCR 2015;3(3):481629.

[22] Vrabec R, Vatavuk Z, Pavlovic D, et al. Ocular findings in patients with chronic renal failure undergoing haemodialysis. Coll Antropol 2005;29(Suppl 1):95-8.
[23] Bourquia A, Zaghloul K, Berrada S, et al. Ophthalmologic manifestations in patients under chronic hemolialysis. Ann Med Interne (Paris) 1992;143(1):18-21.

[24] Pahor D, Hojs R, Gracner B. Conjunctival and corneal changes in chronic renal failure patients treated with maintenance hemodialysis. Ophthalmologica 1995;209:14-6.

[25] Michaud PA. Corneal and conjunctival deposits in the eyes of patients treated with periodic haemodialysis. Study of 47 patients. Klin Monbl Augenheilkd 1978;172(4):523-6. 